\title{
Aplicações clínicas da tomografia computadorizada cone beam na endodontia: revisão de literatura
}

\author{
Clinical applications of cone beam computed tomography in endodontics: literature review \\ Aplicaciones clínicas de la tomografía computarizada de haz cónico en endodoncia: revisión de la \\ literatura
}

Recebido: 17/12/2021 | Revisado: 24/12/2021 | Aceito: 04/01/2022 | Publicado: 05/01/2022

Rita de Cássia Pereira Silva

ORCID: https://orcid.org/0000-0003-3919-8213 Centro Universitário Cesmac, Brasil E-mail: nicassiapereira@gmail.com

Mariana dos Santos Bezerra

ORCID: https://orcid.org/0000-0003-4887-3356

Centro Universitário Cesmac, Brasil

E-mail: marianasantosb@ hotmail.com

Géssyca Luyse Procópio Gonzaga

ORCID: https://orcid.org/0000-0003-2111-5459 Centro Universitário Cesmac, Brasil

E-mail: g.luyse@hotmail.com

Ana Beatriz Macêdo Fonseca

ORCID: https://orcid.org/0000-0002-1315-8849 Centro Universitário Cesmac, Brasil

E-mail: anab.macedof@gmail.com

Mayane Karyne Amâncio da Silva

ORCID: https://orcid.org/0000-0001-7371-8812 Centro Universitário Cesmac, Brasil

E-mail: mk-amancio@hotmail.com

Islyane de Albuquerque Santos

ORCID: https://orcid.org/0000-0003-4223-4123 Centro Universitário Cesmac, Brasil

E-mail: islyane_albuquerque@ hotmail.com

Samara Verçosa Lessa

ORCID: https://orcid.org/0000-0002-0544-4095

Centro Universitário Cesmac, Brasil

E-mail: samara_lessaa@hotmail.com

\begin{abstract}
Resumo
$\mathrm{Na}$ endodontia, o exame por imagem é essencial durante todas as etapas do tratamento. Neste sentido, o exame radiográfico e a tomografia computadorizada cone beam (TCCB), são métodos complementares utilizados no diagnóstico e planejamento do tratamento endodôntico. Com o advento da TCCB na terapia endodôntica, por se tratar de exame que utiliza a radiação e permite obter a reprodução de uma secção do corpo humano em quaisquer uns dos três planos do espaço, ou seja, em três dimensões (3D), com mínima distorção e dose de radiação significantemente reduzida em comparação à tomografia computorizada fan beam (tradicional), permitindo uma maior compreensão da anatomia e mensuração com a destruição de tecido por patologias perirradiculares. Assim, o presente trabalho tem como objetivo analisar o uso da tomografia computadorizada cone beam no tratamento endodôntico, tendo em vista sua importância na aplicabilidade clínica para proporcionar um melhor diagnóstico, planejamento, prognóstico, vantagens, desvantagens, limitações e contraindicações. Dessa forma, a TCCB surge como uma tecnologia que vem se aproximando do cirurgião-dentista, e suprindo as limitações radiográficas durante os passos operatórios. A pesquisa foi desenvolvida por meio de uma revisão bibliográfica de literatura entre os anos 2006 até 2021, consultados nas bases de dados do SciELO (Scientific Electronic Library Online), PubMed e LILACS (Literatura Latino-americana e do Caribe em Ciências da Saúde).
\end{abstract}

Palavras-chave: Tomografia computadorizada de feixe cônico; Imageamento tridimensional; Diagnóstico bucal.

\section{Abstract}

In endodontics, imaging is essential during all stages of treatment. In this sense, radiographic examination and cone beam computed tomography (CBCT) are complementary methods used in the diagnosis and planning of endodontic treatment. With the advent of CBCT in endodontic therapy, as it is an exam that uses radiation and allows the reproduction of a section of the human body in any of the three planes of space, that is, in three dimensions (3D), with 
a minimum distortion and significantly reduced radiation dose compared to fan beam computed tomography (traditional), allowing a greater understanding of anatomy and measurement with tissue destruction by periradicular pathologies. Thus, this study aims to analyze the use of cone beam computed tomography in endodontic treatment, considering its importance in clinical applicability to provide a better diagnosis, planning, prognosis, advantages, disadvantages, limitations and contraindications. Thus, CBCT emerges as a technology that has been approaching the dentist, and overcoming the radiographic limitations during the operative steps. The research was developed through a literature review of literature between the years 2006 to 2021, consulted in the databases of SciELO (Scientific Electronic Library Online), PubMed and LILACS (Latin American and Caribbean Literature in Health Sciences).

Keywords: Cone beam computed tomography; Three-dimensional imaging; Oral diagnosis.

\section{Resumen}

En endodoncia, la imagenología es esencial durante todas las etapas del tratamiento. En este sentido, el examen radiográfico y la tomografía computarizada de haz cónico (CBCT) son métodos complementarios utilizados en el diagnóstico y planificación del tratamiento endodóntico. Con el advenimiento del CBCT en la terapia endodóntica, ya que es un examen que utiliza radiación y permite la reproducción de una sección del cuerpo humano en cualquiera de los tres planos del espacio, es decir, en tres dimensiones (3D), con un mínimo distorsión y dosis de radiación significativamente reducida en comparación con la tomografía computarizada en abanico (tradicional), lo que permite una mayor comprensión de la anatomía y medición con destrucción de tejido por patologías perirradiculares. Así, este estudio tiene como objetivo analizar el uso de la tomografía computarizada de haz cónico en el tratamiento endodóntico, considerando su importancia en la aplicabilidad clínica para brindar un mejor diagnóstico, planificación, pronóstico, ventajas, desventajas, limitaciones y contraindicaciones. Así, la CBCT surge como una tecnología que se ha ido acercando al odontólogo, superando las limitaciones radiográficas durante los pasos operatorios. La investigación se desarrolló a través de una revisión bibliográfica de la literatura entre los años 2006 al 2021 , consultada en las bases de datos de SciELO (Scientific Electronic Library Online), PubMed y LILACS (Literatura Latinoamericana y Caribeña en Ciencias de la Salud).

Palabras clave: Tomografía computarizada de haz cónico; Imágenes tridimensionales; Diagnóstico bucal.

\section{Introdução}

O tratamento endodôntico tem como finalidade a preservação do dente através da prevenção, diagnóstico, prognóstico, tratamento e a avaliação das alterações da polpa e dos tecidos perirradiculares. Sendo definido seu diagnóstico e realizado o acesso ao canal radicular, o tratamento endodôntico consiste em três etapas principais de controle da infecção: preparo químico-mecânico, medicação intracanal e a obturação do sistema de canais radiculares.

$\mathrm{Na}$ endodontia, os exames radiográficos convencionais são indispensáveis durante todas as etapas do tratamento. No entanto, por ser uma imagem bidimensional, a radiografia periapical, mesmo sendo a mais utilizada, pode apresentar limitações que acabam dificultando para o cirurgião-dentista um correto planejamento (Luquetti; Santos, 2020), como distorções e sobreposições de imagens, impossibilitando uma correta visualização das estruturas anatômicas. Para superar estas limitações durante o diagnóstico e planejamento, tem sido utilizada a Tomografia Computadorizada Cone Beam (TCCB), proporcionando uma visualização tridimensional das imagens radiográficas. Além de possuir dose de radiação reduzida em comparação à Tomografia Computorizada tradicional Fan Beam (TCFB), produzindo imagens 3D, com mínima distorção (Dias et al., 2020).

A TCCB vem proporcionando um grande avanço na odontologia, sendo um importante recurso auxiliar em diversas especialidades odontológicas, como, na ortodontia, implantodontia, periodontia, cirurgia, traumatologia bucomaxilofacial, em exames da ATM e na endodontia, onde nos últimos anos teve um aumento significante na utilização dessa técnica (Moura et al., 2018).

Essa técnica permite a identificação de processos patológicos como cistos, tumores e corpos estranhos, na visualização de dentes inclusos, dentes supranumerários, seios paranasais, os componentes ósseos da articulação temporomandibular, para diagnosticar lesões traumáticas e mostrar os sítios ósseos para implantes dentários, tendo assim, seu uso em diversas áreas da odontologia (Dias et al., 2020).

Segundo os autores Moura et al. (2018) e Luquetti e Santos (2020), atualmente, o uso da TCCB está mais acessível aos endodontistas, uma vez que no dia a dia os profissionais estão lidando com casos mais complexos, tornando-se 
fundamental a utilização dessa técnica, já que ela fornece um diagnóstico mais preciso e assim, consecutivamente, está tendo um aumento de profissionais para esse tipo de exame por imagem.

Dessa forma, a TCCB apresenta-se como um método valioso para auxiliar no diagnóstico endodôntico, por ser uma técnica tridimensional que utiliza a radiação x, o que não é possível na radiografia periapical. Quando comparada a tomografia convencional, a TCCB utiliza doses menores de radiação (1/6 da TCFB), mostra as estruturas ósseas com volume, imagens concisas, semelhante a radiografia panorâmica. Além disso, o alcance das imagens leva uma maior fidelidade ao diagnóstico, planejamento e prognóstico dos pacientes (Luquetti \& Santos, 2020 \& Garcez, 2020).

Especificamente na endodontia, atua com a finalidade de propiciar um melhor diagnóstico por imagem e consecutivamente um melhor planejamento e prognóstico, onde tem sido indicada para avaliação da anatomia do canal radicular, avaliação de anomalias do desenvolvimento, preparação do canal radicular, obturação radicular, retratamento, detecção de lesões periapicais, cirurgia periapical, fraturas radiculares, diagnóstico de lesões periapicais, análise de reabsorções radiculares e planejamento pré-cirúrgico (Costa et al., 2009).

Diante do exposto, o presente trabalho tem como objetivo analisar o uso da Tomografia Computadorizada Cone Beam no tratamento endodôntico, tendo em vista sua importância na aplicabilidade clínica para proporcionar um melhor diagnóstico, planejamento, prognóstico, vantagens, desvantagens, limitações e contraindicações. Dessa forma, a tomografia computadorizada cone beam surge como uma tecnologia que vem se aproximando do cirurgião-dentista, e suprindo as limitações radiográficas durante os passos operatórios.

\section{Metodologia}

Trata-se de uma revisão bibliográfica, que segundo Botelho, Cunha \& Macedo (2011), requer a produção de um resumo em diferentes tópicos contendo experiencias anteriores ou literatura teórica, oferecendo uma compreensão ex tensiva de um assunto específico, objetivando analisar e sintetizar vários estudos publicados para formação de novos conhecimentos, com bases nos resultados dos estudos publicados anteriormente, para preparar uma revisão integrativa, as etapas devem ser representadas de forma evidente, etapas como a identificação do tema, estabelecimentos dos critérios de inclusão e exclusão, identificação dos estudos pré-selecionados e selecionados, categorização dos estudos, analise e interpretação dos resultados e apresentação da revisão/síntese do conhecimento.

O levantamento bibliográfico foi realizado por meio eletrônico, onde foram utilizadas as seguintes bases de dados SciELO (Scientific Electronic Library Online), PubMed e LILACS (Literatura Latino-americana e do Caribe em Ciências da Saúde). Onde foram selecionados 28 artigos científicos entre os anos de 2006 a 2021, sendo usado como descritores (Tomografia computadorizada de feixe cônico; Imageamento Tridimensional; e Diagnóstico Bucal), onde teve como critérios de inclusão artigos que foram publicados entre 2006 a 2021, artigos publicados nos idiomas português, inglês, e artigos científicos de acesso livre. 
Figura 1: Fluxograma do processo de busca e seleção dos artigos para a revisão de litertura.
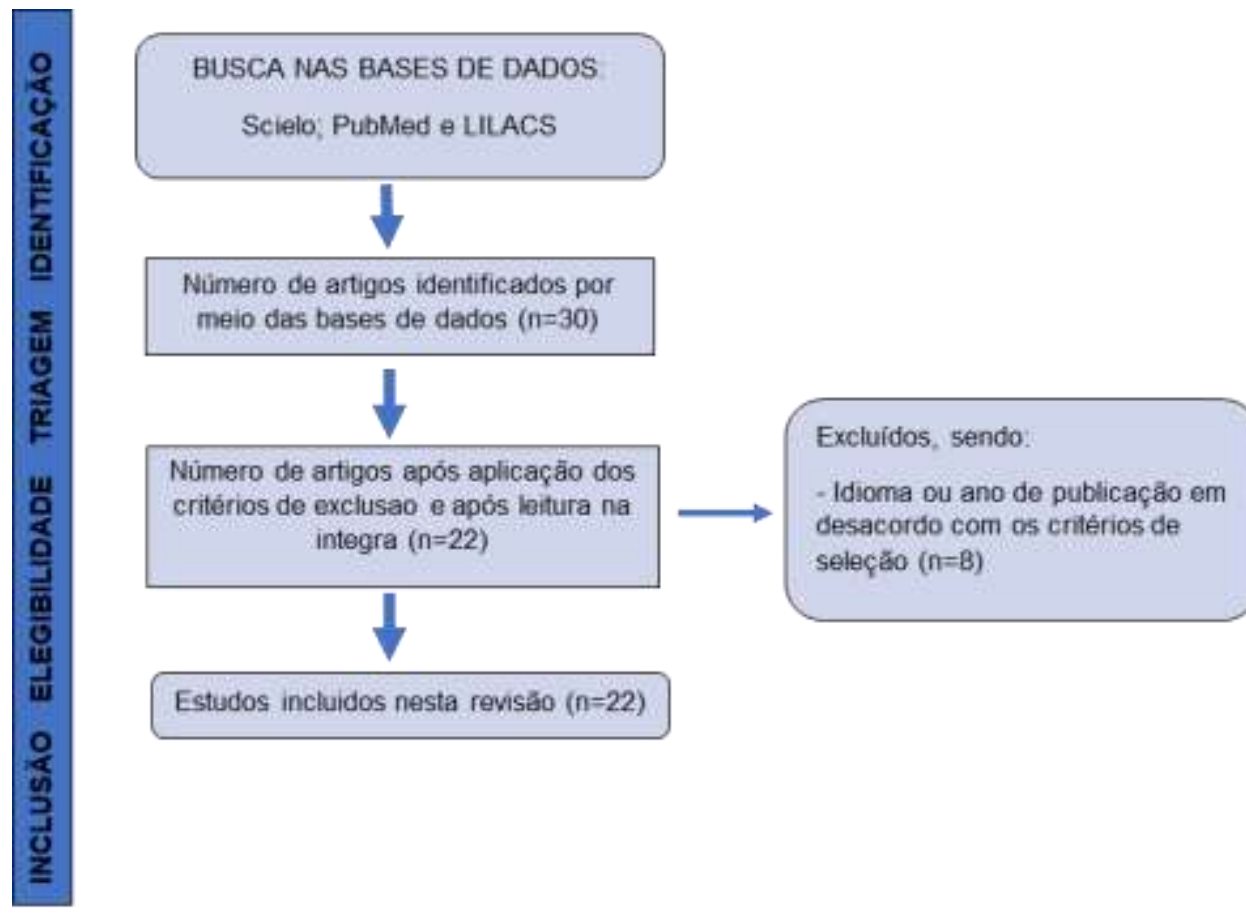

Estudos incluidos nesta revisăo $(n=22)$

Fonte: Autores.

O fluxograma acima tem o objetivo de relatar a seleção dos artigos que compuseram a amostra deste estudo, demonstrando as etapas de forma objetiva, com as fases de identificação dos artigos nas bases de dados; seleção destes, através de uma triagem e com a exclusão daqueles que estavam em desacordo com os critérios de seleção.

\section{Resultados e Discussão}

A amostra final constitui-se de 22 artigos, orientados pela metodologia descrita nesta pesquisa, onde na tabela abaixo sintetizamos 6 artigos que integraram o estudo, destacando as informações como título, autores, ano, objetivos e os principais resultados, respectivamente.

Tabela 1: Distribuição dos artigos de acordo com os objetivos e principais resultados.

\begin{tabular}{|c|c|c|c|c|}
\hline $\mathbf{N}^{\mathbf{0}}$ & Título do artigo & Autores/Ano & Objetivos & Principais Resultados \\
\hline 1 & $\begin{array}{l}\text { Tomografia cone } \\
\text { beam na endodontia } \\
\text { contemporânea }\end{array}$ & $\begin{array}{l}\text { Dias, S., Meirelles, V., } \\
\text { Caetano, W., Pereira, } \\
\text { P., Figueiredo, S., } \\
\text { Gonçalves, L., \& } \\
\text { Soares, R. (2020) }\end{array}$ & $\begin{array}{l}\text { Realizar uma revisão de literatura sobre a } \\
\text { aplicabilidade da tomografia } \\
\text { computadorizada cone beam na } \\
\text { endodontia, demostrando os benefícios da } \\
\text { tomografia computadorizada cone beam } \\
\text { na endodontia, a fim de contribuir para os } \\
\text { trabalhos dos profissionais de odontologia. }\end{array}$ & $\begin{array}{l}\text { a TCCB deve ser considerada nas situações em } \\
\text { que as informações dos exames convencionais } \\
\text { de imagem podem não render uma quantidade } \\
\text { adequada de informações para permitir o } \\
\text { manejo adequado dos problemas endodônticos } \\
\text { [17]. E os endodontistas devem fortalecer o } \\
\text { treinamento, atualizar seus conhecimentos e } \\
\text { familiarizar-se com a tecnologia de TCCB. }\end{array}$ \\
\hline 2 & $\begin{array}{l}\text { Aplicabilidade da } \\
\text { tomografia } \\
\text { computadorizada de } \\
\text { feixe cônico na } \\
\text { endodontia: revisão } \\
\text { de literatura }\end{array}$ & $\begin{array}{l}\text { Luquetti, B., Araújo, } \\
\text { F., \& Santos, C. } \\
(2020)\end{array}$ & & $\begin{array}{l}\text { Foi cofirmada a importância de se utilizar a } \\
\text { TCFC como recurso auxiliar no planejamento } \\
\text { do tratamento endodôntico, das reintervenções e } \\
\text { nas cirurgias parendodônticas, bem como no } \\
\text { acompanhamento após o tratamento realizado, } \\
\text { fornecendo imagens precisas e de grande } \\
\text { acurácia. }\end{array}$ \\
\hline 3 & $\begin{array}{l}\text { Quando indicar a } \\
\text { tomografia na } \\
\text { endodontia: } \\
\text { vantagens, }\end{array}$ & $\begin{array}{l}\text { Dornelas, C. C. P., \& } \\
\text { Cornélio, A. L. G. } \\
(2021)\end{array}$ & 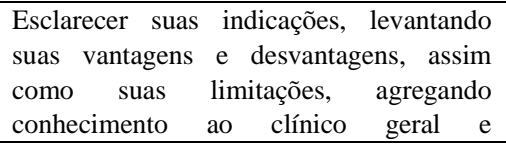 & $\begin{array}{l}\text { A tomografia é de suma importância para o } \\
\text { planejamento cirúrgico afim de minimizar } \\
\text { riscos e aumentar as chances de sucesso, assim } \\
\text { como para os planejamentos de endodontia }\end{array}$ \\
\hline
\end{tabular}




\begin{tabular}{|c|c|c|c|c|}
\hline & $\begin{array}{l}\text { desvantagens e } \\
\text { limitações }\end{array}$ & & $\begin{array}{l}\text { especialista em endodontia, oferecendo um } \\
\text { tratamento melhor, mais seguro e com } \\
\text { maior índice de sucesso aos seus } \\
\text { pacientes. }\end{array}$ & $\begin{array}{l}\text { guiada, como o endoguide por exemplo, guia } \\
\text { confeccionada para auxilio em casos de canais } \\
\text { extremamente calcificados. }\end{array}$ \\
\hline 4 & $\begin{array}{l}\text { Tomografia } \\
\text { computadorizada de } \\
\text { feixe cônico (Cone } \\
\text { beam): entendendo } \\
\text { este novo método de } \\
\text { diagnóstico por } \\
\text { imagem com } \\
\text { promissora } \\
\text { aplicabilidade na } \\
\text { Ortodontia }\end{array}$ & $\begin{array}{l}\text { Garib, D. G., } \\
\text { Raymundo Jr., R., } \\
\text { Raymundo, M. V., } \\
\text { Raymundo, D. V., \& } \\
\text { Ferreira, S. N. (2007) }\end{array}$ & $\begin{array}{l}\text { Instruir o profissional da área odontológica } \\
\text { em relação a tomografia computadorizada, } \\
\text { abrangendo informações referentes à } \\
\text { aquisição de imagens, dose de radiação e } \\
\text { interpretação do exame tomográfico, com } \\
\text { diferenciação entre a TC tradicional e a } \\
\text { TCFC. }\end{array}$ & $\begin{array}{l}\text { Por ter um custo e doses de radiação menores, } \\
\text { percebe-se um aumento do uso e crescimento da } \\
\text { TC de feixe cônico advindo em um futuro bem } \\
\text { próximo na Odontologia. Com a realização de } \\
\text { várias pesquisas e assim novos conhecimentos } \\
\text { gerados pela visão tridimensional do crânio e da } \\
\text { face, o que se espera é que a TCFC modifique } \\
\text { conceitos e paradigmas, redirecionando metas e } \\
\text { planos terapêuticos. }\end{array}$ \\
\hline 5 & $\begin{array}{l}\text { Uso de tomografia } \\
\text { computadorizada no } \\
\text { diagnóstico de } \\
\text { fraturas radiculares }\end{array}$ & $\begin{array}{l}\text { Pulcino, M. M., } \\
\text { Popolim, I. N., \& } \\
\text { Picoli, F. (2016). }\end{array}$ & $\begin{array}{l}\text { Fazer o levantamento bibliográfico sobre } \\
\text { tomografia computadorizada e seu uso } \\
\text { atualmente no diagnóstico de fraturas } \\
\text { radiculares. }\end{array}$ & $\begin{array}{l}\text { Para um correto diagnóstico de fraturas } \\
\text { radiculares é necessário associar todas as } \\
\text { informações, desde o exame clínico à exames } \\
\text { complementares precisos como a tomografia } \\
\text { computadorizada. Esta técnica é considerada } \\
\text { um método seguro, podendo-se obter } \\
\text { reconstruções de imagem tridimensional, } \\
\text { aumentando a eficiência de diagnóstico. }\end{array}$ \\
\hline 6 & $\begin{array}{l}\text { Contextualização } \\
\text { histórica da } \\
\text { radiologia } \\
\text { odontológica }\end{array}$ & $\begin{array}{l}\text { Bolner, R. C. N. C. } \\
\text { (2011). }\end{array}$ & $\begin{array}{l}\text { Realizar uma revisão da literatura sobre a } \\
\text { contextualização histórica da radiologia } \\
\text { odontológica para mostrar aos } \\
\text { profissionais da área da saúde, } \\
\text { principalmente aos cirurgiões dentistas, a } \\
\text { importância da descoberta dos raios X e } \\
\text { sua evolução dentro da odontologia. }\end{array}$ & $\begin{array}{l}\text { O advento dos raios X é uma das maiores } \\
\text { descobertas científicas da humanidade, pois } \\
\text { possibilitou a introdução e o uso da imagem no } \\
\text { diagnóstico, planejamento e tratamento das } \\
\text { doenças bucais. } \\
\text { Aliado a isto, os avanços tecnológicos } \\
\text { possibilitaram a criação de aparelhos digitais de } \\
\text { raios X, mais recentemente, a utilização da } \\
\text { tomografia computadorizada de feixe cônico } \\
\text { como meio de diagnóstico na odontologia. }\end{array}$ \\
\hline
\end{tabular}

Fonte: Autores.

Com a descoberta da radiografia, em 1895 por Wilhelm Conrad Röentgen, onde apresentou sua descoberta à sociedade de Física Médica de Wurzburg, na Alemanha as imagens do primeiro teste, em que obteve radiografias experimentais, e dentre essas imagens, continham a radiografia da mão de sua esposa. No ano seguinte, Röentgen foi eleito o responsável por essa descoberta, o que o levou a receber o Prêmio Nobel de Física, em 1901, onde denominou de raios x (Carvalho, 2020).

Na odontologia, o dentista Otto Walkhoff, realizou a primeira radiografia intrabucal usando uma placa de vidro com emulsão fotográfica envolvida em papel preto de lenço de borracha. A radiografia foi realizada na sua própria boca, com um tempo de exposição de aproximadamente 25 minutos (Bolner, 2011).

Em 1898, o Dr. José Carlos Ferreira Pires obteve um aparelho de raios x, que foi enviado até Minas Gerais, sendo essa a primeira ocorrência da radiografia no Brasil (Carvalho, 2020; Bolner, 2011).

Em 1972, o bioquímico e físico Allan McLeod e o engenheiro Godfrey Hounsfield inventaram a tomografia computadorizada (TC), revolucionando a área médica e facilitando os meios de diagnóstico, utilizando rx e o computador e assim obtendo imagens tridimensionais por meios de cortes milimétricos dos planos axial, sagital e coronal e desta maneira, eliminando a sobreposição de estruturas anatômicas e assim conseguindo diferenciar tecidos moles e estruturas ósseas (Dornelas; Cornélio, 2020).

Com o avanço da tecnologia, os pesquisadores Mozzi et al, da universidade de Verona na Itália, em 1998 relataram os resultados preliminares de um novo aparelho de TC para imagens odontológicas diminuindo o campo de visão para um feixe em forma de cone oferecendo uma qualidade de imagem superior e com menos distorção quando comparada a TC tradicional (Bolner, 2011; Dornelas \& Cornélio, 2020). 
A tomografia computadorizada é dividida em dois tipos: tomografia tradicional de feixe em leque (fan beam) e tomografia volumétrica de feixe cônico (cone beam) (Cavalcante et al., 2012).

A tomografia computadorizada fan beam (TCFB) é utilizada na medicina, e a tomografia computadorizada cone beam (TCCB) é utilizada na Odontologia (Wanzeler et al., 2016).

A TCCB utiliza um feixe cônico de radiação associado a um receptor de imagens tridimensional. Nesse método, o conjunto, fonte de raios $\mathrm{X}$ e receptor de imagens gira $360^{\circ}$, uma única vez em volta da região de interesse. No decorrer desse giro, múltiplas projeções tridimensionais em ângulos diferentes são obtidas e enviadas ao computador. A partir dessa imagem tridimensional, cortes nos três planos do espaço podem ser obtidos (Scarfe et al., 2006).

A TCFB, necessita de várias voltas, ocasionando maior exposição do paciente à radiação devido ao seu feixe de raios $\mathrm{X}$, a TCCB precisa de apenas um giro ao redor da área de interesse, para conseguir as informações necessárias para a construção das imagens (Farman; Scarfe, 2006).

Alguns autores afirmam que a dose de radiação (exposição) emitida pelo aparelho da TCCB varia de acordo com o modelo comercial do aparelho, espessura dos cortes e ajustes técnicos indicados durante a tomada radiográfica, como: tempo de exposição, miliamperagem e quilovoltagem. Logo, a TCCB possui dose de radiação significativamente menor quando comparada com a TC tradicional, exame periapical de boca inteira ou cerca de quatro a quinze vezes, a dose de uma radiografia panorâmica (Garibe et al., 2007). Porém, deve ser avaliada a decisão de submeter o paciente a radiação, tendo como princípio de que este será submetido apenas a dosagem necessária, para alcançar o diagnóstico (Costa et al., 2009).

Todos os artigos descreveram a eficiência da TCCB em relação a outros exames de imagem, deixando bem claro a melhor opção para auxílio no diagnóstico (Lima \& Rezende, 2011). A TCCB é muito eficiente na endodontia e nas demais áreas da odontologia, porém, devido ao seu alto custo, não foi difundido na odontologia. Assim, só deve ser utilizada quando o Rx não for esclarecedor (Pulcino et al., 2016).

Em comparação as radiografias convencionais que geram em um único plano todas as estruturas através dos raios x, a TC exibe as estruturas em profundidade, exibindo imagens em "fatias" do corpo humano e assim permitindo enxergar todas as estruturas em camadas, principalmente tecidos mineralizados, conseguindo assim enxergar suas irregularidades tridimensionalmente (Dias et al., 2020).

Dias et al. (2020) e Scarfe et al. (2006), a unidade que compõe a imagem tomográfica é denominada de voxel (volume) e coincide com a menor unidade da imagem na espessura do corte. O voxel é classificado como isométrico, ou seja, apresenta altura, largura e profundidade de dimensões iguais. E, assim como (Garibe et al., 2007) afirmam que cada lado do voxel possuem dimensão submilimétrica. Portanto, a imagem da radiografia contém boa resolução, e como consequência, permite a diferenciação entre as estruturas dentárias, esmalte, dentina, cavidade pulpar e cortical alveolar, diferentemente dos exames radiográficos convencionais.

Luquetti; Santos (2020) e Dias et al. (2020), outro fator que estabelece uma melhor resolução de imagens e apresenta um melhor campo de visão (FOV). O FOV avalia a região de interesse em alta resolução e maior precisão, e consequentemente não expõe o paciente a radiação desnecessária. Os feixes de raios x são em forma de leque, portanto, adquiri "fatias" de imagens individuais do FOV, e ao reunir essas "fatias" obtém as imagens em 3D.

Luquetti; Santos (2020), os tomógrafos de feixe cônico são classificados pelo tamanho do seu FOV, e se subdividemse em: aparelhos de pequeno volume, aparelhos de grande volume e aparelhos de grande e pequeno volume. Os aparelhos de pequeno volume, que possuem um FOV de até 8x8cm, são mais indicados nos casos em que a imagem de alta resolução de uma área específica é necessária, como é a caso da Endodontia.

Segundo Durack e Patel (2012), o uso da TCCB tem beneficiado na visualização de fraturas radiculares e no tratamento de traumas. E tem sido de ampla importância na visualização e localização das reabsorções, assim facilita análise 
das estruturas envolvidas (Costa et al., 2009). Podendo ajudar ainda no diagnóstico de lesões perirradiculares. Isto porque o sistema de imagens cone beam, por ser mais sensível que a radiografia convencional, se destaca sendo útil na detecção de periodontite apical, com relevantes informações sobre a destruição óssea periapical associada à endodontia, principalmente quando os sintomas clínicos, sinais e evidências radiográficas convencionais são inconclusivos (Durack; Patel, (2012). Além de proporcionar melhor qualidade de imagem em relação às radiografias periapicais, ela distingue estruturas dentárias e periféricas (Lima \& Rezende, 2011).

Portanto, na Endodontia, a TCCB auxilia no tratamento do canal radicular em várias situações clínicas, sendo utilizada no diagnóstico diferencial entre patologias de origem endodôntica e não-endodôntica, na avaliação da morfologia do canal radicular e sua localização, assim como em caso de canais calcificados, fraturas alveolares e radiculares, análises de reabsorções interna e externa, perfurações, planejamento endodôntico pré-cirúrgico, avaliação do preparo radicular, obturação, retratamento, detecção de lesões ósseas, posição e tamanho das lesões periapicais e pesquisas endodônticas (Costa et al., 2009).

Estudos apresentam que a TCCB tem obtidos vantagens para detectar as fraturas radiculares horizontais (Miranda et al., 2020), avaliação do sistema de canais radiculares (Matherne et al., 2008), avaliação de reabsorções radiculares, auxiliou no planejamento de cirurgia endodôntica, no diagnóstico de sinusite maxilar odontogênica e no diagnóstico de fraturas radiculares (Hassan et al., 2010).

Ao utilizar a TCCB, o risco à radiação deve ser considerado (Cotton et al., 2007), pois apresenta radiação similar a de um levantamento com radiografias periapicais completo ou equivale a aproximadamente 4-15 vezes a dose de uma radiografia panorâmica. Assim, a decisão de submeter o paciente à radiação deve ser bem avaliada, tendo como princípio de que este será submetido apenas a dose de radiação necessária para realizar um correto diagnóstico e obter um plano de tratamento adequado (Estrela et al., 2008).

A TCCB é utilizada em diversas áreas da odontologia, tais como Endodontia, Periodontia, Implantodontia, Ortodontia, Cirurgia, Traumatologia bucomaxilofacial e avaliação da articulação temporomandibular (Moura et al., 2018).

Adicionalmente, este método permite a identificação de processos patológicos como cistos, tumores e corpos estranhos, a visualização de dentes inclusos, dentes supranumerários, seios paranasais, os componentes ósseos da articulação temporomandibular, diagnosticar lesões traumáticas e mostrar os sítios ósseos para implantes dentários (Araújo et al., 2019).

A avaliação da região de ATM, através de exames radiográficos convencionais, é limitada em virtude da possibilidade de sobreposição das estruturas anatômicas. A TCCB permite examinar com maior exatidão a anatomia da ATM, fornecendo uma imagem sem sobreposições e facilitando a análise do espaço articular, a morfologia óssea e função dinâmica, nas três dimensões (Barghan et al., 2012).

Na última década, os benefícios das imagens resultantes do exame de TCCB na cirurgia oral e maxilofacial têm demonstrado avanço contínuo. A introdução da TCCB na área cirúrgica contribuiu, consideravelmente, para uma melhora na conduta da cirurgia bucomaxilofacial, visto que a imagem radiográfica pode ser empregada na construção de modelos de prototipagem, podendo ser utilizada como auxílio na colocação de implante dentário ou reconstrução da mandíbula (Ahmad et al., 2012).

Patel et al. (2009) prepararam artificialmente defeitos ósseos na região periapical da raiz distal de molares inferiores, e comprovaram a precisão e eficácia da CBCT na deteç̧ão destes defeitos, quando comparada com a radiografia digital.

Cymerman et al. (2011) demonstraram a eficácia da CBCT no diagnóstico da sinusite maxilar de origem odontogênica, durante a avaliação de 3 casos clínicos onde os pacientes apresentavam sinusite maxilar grave, colaborando para o plano de tratamento e realização da terapêutica adequada.

D`Addazio et al. (2010) mostram que a TCCB é um método preciso para auxiliar no diagnóstico e planejamento das intervenções fundamentais na realização de um tratamento cirúrgico. Os autores relataram um caso clínico de um paciente que 
apresentava na região anterior da maxila uma lesão cística, de dimensões expressivas, cuja cirurgia foi planejada e executada após a visualização das margens da lesão por imagens de TCCB. Dessa forma, concluíram que a TCCB proporcionou um planejamento e tratamento da cirurgia uma maior exatidão, pois permite a visualização tridimensional das estruturas.

O estudo realizado por (Estrela et al., 2008) comparou o diagnóstico de lesão periapical crônica através do método radiográfico periapical, panorâmico e TCCB de 1058 prontuários, que apresentava o registro de exame por imagem de pacientes com infecções endodônticas. Para a detecção precoce de lesão periapical os usos de imagens tomográficas proporcionaram melhores resultados. Em casos de reabsorção óssea avançada a técnica radiográfica mostra-se eficiente e com relação custo-benefício segura.

Observou-se que atualmente possuem poucas evidências cientificas, e poucos artigos foram publicados no idioma português, possivelmente ao fato de ser uma técnica pouco disseminada. Recomenda-se aos profissionais da área odontológica a realização de palestras, cursos de aperfeiçoamento, post nas redes sociais, a fim de promover a disseminação da TCCB no Brasil. Deste modo, frente aos trabalhos revisados, conseguimos certificar a importância de empregar a TCCB no planejamento, diagnóstico, bem como no prognóstico, proporcionando imagens de qualidades, com mínima distorção.

\section{Considerações Finais}

A TCCB mostrou ser um importante método auxiliar para a prática endodôntica, principalmente em casos complexos. Contribuindo na averiguação de estruturas anatômicas, identificação de lesões periapicais, localização de canais radiculares, reabsorções radiculares, fraturas radiculares horizontais, confecção de guias virtuais endodônticos e em cirurgias parendodônticas, fornecendo informações precisas para um melhor diagnóstico, planejamento e no prognóstico. Desta forma a TCCB é de grande valia no diagnóstico diferencial e devem ser solicitadas somente quando técnicas radiográficas convencionais não são suficientes para o correto diagnóstico, devido ao seu elevado custo.

Portanto, é imprescindível que novos estudos sobre esse assunto seja realizado, para que possam conhecer e compreender o uso da TCCB na prática clínica, bem como sua importância, para assim facilitar a realização dos tratamentos endodônticos. Espera-se que no futuro essa técnica de diagnóstico venha trazer mais benefícios para a odontologia, afim de reproduzir resultados mais rápidos e eficazes e assim contribuir na promoção de saúde.

\section{Referências}

Ahmad, M., Jenny, J., \& Downie, M. (2012). Application of cone beam computed tomography in oral and maxillofacial surgery. Australian Dental Journal, 57, 82-94. https://doi.org/10.1111/j.1834-7819.2011.01661.x

Araújo, T. L. de B., Barros, J. F. de M. C., Lopes, S. V. F., Silva, E. F. da, \& Freitas, S. A. P. (2019). Aplicação da tomografia computadorizada de feixe cônico no diagnóstico odontológico - revisão de literatura. Revista uningá, 56(s7), 43-56. http://revista.uninga.br/index.php/uninga/article/view/3148/2110

Barghan, S., Tetradis, S., \& Mallya, S. (2012). Application of cone beam computed tomography for assessment of the temporomandibular joints. Australian Dental Journal, 57, 109-118. https://doi.org/10.1111/j.1834-7819.2011.01663.x

Bolner, R. C. N. C. (2011). Contextualização histórica da radiologia odontológica. www.lume.ufrgs.br. https://www.lume.ufrgs.br/handle/10183/48925

Carvalho, R. J. (2021). A importância da tomografia computadorizada na endodontia. RDUnicesumar. http://rdu.unicesumar.edu.br/handle/123456789/7862

Cavalcante, J. R., Diniz, D. N., Queiroz, R. P. de M., Carreira, P. F. S., \& Luna, A. G. B. (2012). Aplicação da tomografia na CTBMF: Relatos de caso. Revista de Cirurgia E Traumatologia Buco-Maxilo-Facial, 12(2), 53-58. http://revodonto.bvsalud.org/scielo.php?pid=S1808$52102012000200010 \&$ script=sci_arttext

Costa, C. C. D. A., Moura-Netto, C., Koubik, A. C. G. A., \& Michelotto, A. L. D. C. (2009). Aplicações clínicas da tomografia computadorizada cone beam na endodontia. J. Health Sci. , 279-286.

Cotton, T., Geisler, T., Holden, D., Schwartz, S., \& Schindler, W. (2007). Endodontic Applications of Cone-Beam Volumetric Tomography. Journal of Endodontics, 33(9), 1121-1132. https://doi.org/10.1016/j.joen.2007.06.011

Cymerman, J. J., Cymerman, D. H., \& O’Dwyer, R. S. (2011). Evaluation of Odontogenic Maxillary Sinusitis Using Cone-Beam Computed Tomography: Three Case Reports. Journal of Endodontics, 37(10), 1465-1469. https://doi.org/10.1016/j.joen.2011.06.015 
D’Addazio, P. S. dos S., Assis, N. M. S. P., Campos, C. N., Bastos, T. dos R., \& Lopes, R. de M. (2010). O uso da tomografia cone beam no auxílio ao diagnóstico e planejamento de cirurgia periapical: relato de caso clínico. Odontologia Clínico-Científica (Online), 9(4), 377-380. http://revodonto.bvsalud.org/scielo.php?pid=S1677-38882010000400021\&script=sci_arttext

Dias, S., Meirelles, V., Caetano, W., Pereira, P., Figueiredo, S., Gonçalves, L., \& Soares, R. (2020). Tomografia cone beam na endodontia contemporânea. Revista Científica Da UNIFENAS - ISSN: 2596-3481, 2(2). https://revistas.unifenas.br/index.php/revistaunifenas/article/view/505

Dornelas, C. C. P., \&Cornélio, A. L. G. (2021). Quando indicar a tomografia na endodontia: vantagens, desvantagens e limitações. RIUuniceplac. https://dspace.uniceplac.edu.br/handle/123456789/468

Durack, C., \& Patel, S. (2012). Cone beam computed tomography in endodontics. Brazilian Dental Journal, 23(3), 179-191. https://doi.org/10.1590/s010364402012000300001

Estrela, C., Bueno, M. R., Leles, C. R., Azevedo, B., \& Azevedo, J. R. (2008). Accuracy of Cone Beam Computed Tomography and Panoramic and Periapical Radiography for Detection of Apical Periodontitis. Journal of Endodontics, 34(3), 273-279. https://doi.org/10.1016/j.joen.2007.11.023

Farman, A. G., \& Scarfe, W. C. (2006). Development of imaging selection criteria and procedures should precede cephalometric assessment with cone-beam computed tomography. American Journal of Orthodontics and Dentofacial Orthopedics, 130(2), 257-265. https://doi.org/10.1016/j.ajodo.2005.10.021

Garcez, G. de M. (2020). Aplicações da tomografia computadorizada de feixe cônico na endodontia: revisão de literatura. Repositório digital Maria Izabel. http://repositorio.undb.edu.br/handle/areas/233

Garib, D. G., Raymundo Jr., R., Raymundo, M. V., Raymundo, D. V., \& Ferreira, S. N. (2007). Tomografia computadorizada de feixe cônico (Cone beam): entendendo este novo método de diagnóstico por imagem com promissora aplicabilidade na Ortodontia. Revista Dental Press de Ortodontia E Ortopedia Facial, 12(2), 139-156. https://doi.org/10.1590/s1415-54192007000200018

Hassan, B., Metska, M. E., Ozok, A. R., van der Stelt, P., \& Wesselink, P. R. (2010). Comparison of Five Cone Beam Computed Tomography Systems for the Detection of Vertical Root Fractures. Journal of Endodontics, 36(1), 126-129. https://doi.org/10.1016/j.joen.2009.09.013

Lima, S. M. D. F., \& Rezende, T. M. B. (2011). Benefícios de Exames Tomográficos na endodontia: Revisão de Literatura. Oral Scienes, 3(1), $26-31$.

Luquetti, B. S.; Santos, F. A. C. (2020). APLICABILIDADE DA TOMOGRAFIA COMPUTADORIZADA DE FEIXE CÔNICO NA ENDODONTIA: Revisão de literatura. Universidade de Taubaté. Trabalho de conclusão de curso. Taubaté - SP. http://repositorio.unitau.br/jspui/handle/20.500.11874/3808

Matherne, R. P., Angelopoulos, C., Kulild, J. C., \& Tira, D. (2008). Use of Cone-Beam Computed Tomography to Identify Root Canal Systems In Vitro. Journal of Endodontics, 34(1), 87-89. https://doi.org/10.1016/j.joen.2007.10.016

Miranda, J. K. T., Moraes, M. E. P. de., Padilha, E. M. F., Rocha, A. de O., Santos, D. D. D. dos., Oliveira, A. L. P. de., Silva, F. R. da., Franco, A. V. de M., \& Lins, F. F. (2020). Tomografia computadorizada em endodontia: revisão de literatura. Revista Eletrônica Acervo Saúde, (50), e3238. https://doi.org/10.25248/reas.e3238.2020

Moura, J. R., Silva, N. M. da, Melo, P. H. L. de, \& Lima, S. R. (2018). Aplicabilidade da tomografia computadorizada cone beam na odontologia. Rev. Odontol. Araçatuba (Impr.), 22-27. https://pesquisa.bvsalud.org/portal/resource/pt/biblio-913471

Patel, S., Dawood, A., Mannocci, F., Wilson, R., \& Pitt Ford, T. (2009). Detection of periapical bone defects in human jaws using cone beam computed tomography and intraoral radiography. International Endodontic Journal, 42(6), 507-515. https://doi.org/10.1111/j.1365-2591.2008.01538.x

Pulcino, M. M., Popolim, I. N., \& Picoli, F. (2016). Uso de tomografia computadorizada no diagnóstico de fraturas radiculares. Revista Investigação, 15(1), $110-13$.

Scarfe, W., Farman, A., \& Sukovic, P. (2006). Auteur-ressource Clinical Applications of Cone-Beam Computed Tomography in Dental Practice. 72. http://cda-adc.ca/jadc/vol-72/issue-1/75.pdf

Tokus, Ana. (2015). A diferença entre tomografia Fan Beam e Cone Beam. Raios Xis. https://raiosxis.com/a-diferenca-entre-tomografia-fan-beam-e-conebeam

Wanzeler, A. M. V., Barra, S. G., \& Guedes, F. R. (2016). Aplicação da Tomografia Computadorizada de Feixe Cônico no Diagnóstico de Fraturas Radiculares. Revista Da Faculdade de Odontologia de Lins, 26(1), 19-28. https://doi.org/10.15600/2238-1236/fol.v26n1p19-28 